\title{
Curation as Digital Literacy Practice
}

\author{
By Ibrar Bhatt
}

\section{Source: http://ibrarspace.net/2014/05/21/curation-as-a-digital-literacy-practice/}

I have been busy writing my $\mathrm{PhD}$ so haven't updated this blog for a while. Thesis writing is taking up a lot of my mental space as I get the ideas, storyline and contentions to coalesce and cohere in a manner suitable for such a piece of work.

But initial data analysis has lead me to a series regarding practices of digital literacies during the writing of assignments, and one of them is the concept and practice of 'curation' as a digital literacy, and what the implications are for curation practices to be better understood, theorised, and subsequently harnessed for educational purposes. My $\mathrm{PhD}$ thesis (Bhatt, 2014) contains some ideas that are worth disseminating out to collide with others as part of what I believe is a public conversation. [Aside: see this brief lecture by Steven Johnson on the 'collision' of ideas and the sharing of half-baked hunches] [youtube http://www.youtube.com/watch?v=NugRZGDbPFU]

The word 'curation' comes from the Latin root curare, meaning 'to cure' or 'to take care of' and historically relates to any processes of organisation, collation, judicious selection (usually for presentation), and even curing and preserving. The term has usually been employed to describe such work which is carried out in museum settings, and has now evolved to describe what is often done in digital environments and online spaces (see http://curationnation.org). To better explain curation in digital environments, the information theorist Edward Tufte (1990) provides a useful and elaborate explanation of the kinds of practices that people tend to do in "information thick worlds". To Tufte, these are the abilities to:

\begin{abstract}
Select, edit, single out, structure, highlight, group, pair, merge, harmonize, synthesize, focus, organize, condense, reduce, boil down, choose, categorize, catalog, classify, list, abstract, scan, look into, idealize, isolate, discriminate, distinguish, screen, pigeonhole, pick over, sort, integrate, blend, inspect, filter, lump, skip, smooth, chunk, average, approximate, cluster, aggregate, outline, summarize, itemize, review, dip into, flip through, browse, glance into, leaf through, skim, refine, enumerate, glean, synopsize, winnow the wheat from the chaff, and separate the sheep from the goats.
\end{abstract}

(Tufte, 1990, 50)

Without going into too much detail here in a blog post, but drawing from Tufte, some aspects of my $\mathrm{PhD}$ data reveal different instances of digital curation in the completion of student work, during the writing of assignments. These processes are, as Tufte outlines, about anthologising older content to produce new content and creating a new experience for readers, by giving a new life (or new 'reality') to an older text. This is curation as a set of digital literacy practices.

Everyday examples of such practices include retweeting, 'liking' on Facebook, collating tweets and other updates into thematic collections (e.g. Storify), the rewriting or rehashing of digitally archived previous text for new purposes (sometimes called patch-writing), etc. In this respect, prolific Web users have often made themselves effective digital curators by searching and locating information, then creating a new experience by re-contextualising it. 
A currently famous example is the curation work of Maria Popova, and her blog updates on Brain Pickings. Popova's curation practices are summarised in the diagram below:
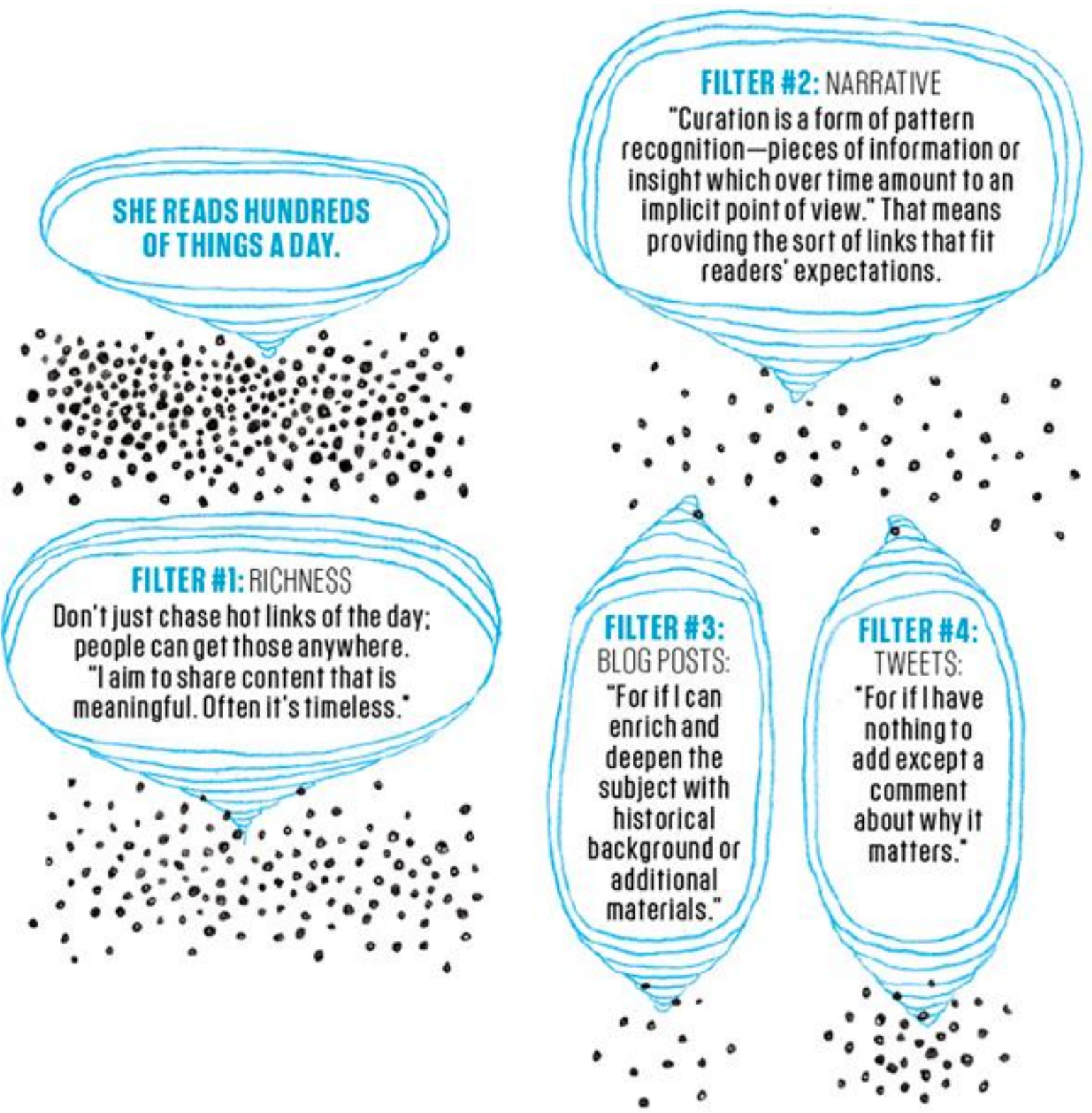

Source: http://www.fastcompany.com/3018236/most-creative-people-2012/51-maria-popova

Digital curation therefore is not just about finding relevant material, although that is a significant part of it, but is also about creating a specific and unique experience by utilising the resulting materials which then become contextualised within a new space. A curator, therefore, whether she is a journalist-by-proxy such as Popova or a student completing an assignment in a classroom, not only collects and interprets, but also creates a new experience with it. In this respect, curation is a process of problem solving, re-assembling, re-creating, and stewardship of other people's writing. Breathing new life into older texts is a complex skill and allows a reader to enter into a conversation with the writers of those texts, in a Bakhtinian sort of way - all writing contains the voices of other authors. How the processes of curation can lead to new forms of writing, and how this can a) be acknowledged, and 


\section{b) incorporated into the ways students are assessed on their writing then becomes a challenge.}

My research is influenced by the field of Science and Technology Studies (STS), revolutionary at the time of its conception for unpacking the 'secret' workings of science and its practices of knowledge creation. Bigum et al (2014) write:

Looking at how scientists actually do science, STS scholars came to see that accounts of science as products of the scientific method glossed the messiness, noncoherence and fuzziness of what went on in the laboratory. To Bruno Latour, in the early days of STS, science was Janus -like, with two contradictory faces: science in the making and ready-made science.

Some aspects of my data (Bhatt, 2014) reveal that in the writing of assignments, previous academic work gets mobilised into action with old assignments used as a validation for current work. Stuff is 'rehashed' and 'remixed' for a new purpose, and subsequently relabelled as 'new' work.

Students' previous, even non-academic, work gets linked to assignments where relevant. Texts written at different times are then fine-tuned, tweaked and glossed for a different intention. Is this cheating? Or working efficiently?

Works of others are collated through prolific Web searching and sometimes linked to, involving signposting and contextualisation through its integration into the new tasks.

In each of these cases, and in MANY other aspects of my research which I will not go into here in a blog post, there is the re-purposing of text in a manner commensurate with curation as defined above. It's not all benign or received as 'honest' work upon assessment, but I am not going to get into that yet. I just want to better understand what is actually happening and what can be done to harness some of these skills: some of these other literacies hidden away within more acknowledged literacies like Matryoshka dolls.

Maybe, if we go back to Bakhtin, all writing and forms of production contain dialogue so are a form of curation?

\section{References:}

Bhatt, I. (2014). A sociomaterial account of assignment writing in Further Education classrooms. (PhD thesis), School of Education, University of Leeds.

Bigum, C., Rowan, L., Wright, S., Hamilton, M. \& Haxell, A. (2014). Looking for black cats and lessons from Charlie: exploring the potential of public click pedagogy (February 2014 version of Working paper) [Online]. Edinburgh. Available: http://chrisbigum.com/downloads/PCP-NLC.pdf [Accessed 9th April 2014].

Tufte, E. R. (1990). Envisioning information, Cheshire, Conn.: Graphics Press. 